\title{
Relaxation-Related Piezoelectric and Dielectric Behavior of $\mathrm{Bi}(\mathrm{Mg}, \mathrm{Ti}) \mathrm{O}_{3}-\mathrm{PbTiO}_{3}$ Ceramic
}

\author{
Min Young Park, Jae-Hoon Ji and Jung-Hyuk Koh *
}

School of Electrical and Electronics Engineering, Chung-Ang University, Heukseok-Ro 84, Seoul 06974, Korea; pmy730@naver.com (M.Y.P.); hoon2441@naver.com (J.-H.J.)

* Correspondence: jhkoh@cau.ac.kr; Tel.: +82-2-820-5311; Fax: +82-2-825-1584

Received: 1 April 2019; Accepted: 1 May 2019; Published: 7 May 2019

\begin{abstract}
Piezoelectric and dielectric materials have attracted much attention for their functional device applications. Despite its excellent piezoelectric properties, the content of lead in piezoelectric materials should be restricted to prevent future environmental problems. Therefore, reduced lead content in piezoelectric materials with similar piezoelectric properties is favorable. In our research, piezoelectric materials with decreased lead content will be studied and discussed. Even though the lead content is decreased in $\mathrm{Bi}\left(\mathrm{Mg}_{0.5} \mathrm{Ti}_{0.5}\right) \mathrm{O}_{3}-\mathrm{PbTiO}_{3}$ ceramics, they show piezoelectric properties similar to that of lead zirconate titanate (PZT)-based materials. We believe this high piezoelectric behavior is related to the relaxation behavior of $\mathrm{Bi}\left(\mathrm{Mg}_{0.5} \mathrm{Ti}_{0.5}\right) \mathrm{O}_{3}-\mathrm{PbTiO}_{3}$ (BMT-PT) ceramics. In this study, $0.62 \mathrm{Bi}\left(\mathrm{Mg}_{0.5} \mathrm{Ti}_{0.5}\right) \mathrm{O}_{3}-0.38 \mathrm{PbTiO}_{3}$ ceramics were prepared by the conventional sintering process. These piezoelectric ceramics were sintered at varying temperatures of $975-1100{ }^{\circ} \mathrm{C}$. Crystallinity and structural properties were analyzed and discussed. X-ray diffraction pattern analysis demonstrated that the optimal sintering temperature was around $1075^{\circ} \mathrm{C}$. A very high Curie temperature of $447{ }^{\circ} \mathrm{C}$ was recorded for $0.62 \mathrm{BMT}-0.38 \mathrm{PT}$ ceramics sintered at $1075^{\circ} \mathrm{C}$. For the first time, we found that the origin of the high Curie temperature, $\mathrm{d}_{33}$, and the dielectric constant is the relaxation behavior of different dipoles in 0.62BMT-0.38PT ceramics.
\end{abstract}

Keywords: piezoelectric; BMT-PT; ceramic

\section{Introduction}

Since the discovery of $\mathrm{Pb}(\mathrm{Zr}, \mathrm{Ti}) \mathrm{O}_{3}$ (PZT) in the 1950s, it has been applied in piezoelectric transducers, actuators, and sensors because of its excellent piezoelectric properties [1]. PZT is also important in new high-precision switchable measurement methods, where dielectric properties are highly important. These methods compensate for environmental effects, voltage offset, frequency drift, and temperature influence, as previously reported in [2-4]. Due to its outstanding piezoelectric and mechanical properties, ceramic-based PZT actuators have received a great deal of attention in the industry. However, it is desirable to use materials with a low lead content to avoid environmental problems [5-8]. Therefore, there is a great need to discover piezoelectric materials that have a low lead content while still having favorable characteristics like those of PZT ceramics.

Recently, $\mathrm{BiFeO}_{3}$-based (BF) perovskite materials have been intensively investigated, owing to their complex electric properties resulting from ferromagnetism and ferroelectricity [9-11]. For high temperature device applications, BF-based materials, $(1-\mathrm{x}) \mathrm{BiMeO}_{3}-\mathrm{xPbTiO}_{3}\left(\mathrm{Me}^{3+}=\mathrm{Fe}, \mathrm{Sc}, \mathrm{Mg}\right.$, In, $\mathrm{Y}, \mathrm{Yb}, \mathrm{Ga}$ ), are attractive. These materials contain metallic components in a distorted perovskite structure, which has a higher Curie temperature between the ferroelectric and paraelectric states than that of PZT ceramics [12]. In particular, bismuth-based perovskite system $\mathrm{Bi}\left(\mathrm{Mg}_{0.5} \mathrm{Ti}_{0.5}\right) \mathrm{O}_{3}-\mathrm{PbTiO}_{3}$ (BMT-PT) ceramics are expected to have a higher Curie temperature with relative polarization and piezoelectric charge coefficient. Since the origin of the $\mathrm{BiMeO}_{3}-\mathrm{PTiO}_{3}$ system is multiferroic material, 
it is expected to have weaker piezoelectric and dielectric properties than the PZT-based system. Despite the higher Curie temperature than that of the PZT system, lower piezoelectric and dielectric properties can be an obstacle for device applications. However, as a lead-containing material, BMT-PT piezoelectric material has similarly excellent piezoelectric properties as PZT, even though it has a low level of lead compared to PZT [13]. The multiferroic and relatively weak ferroelectric properties in the $\mathrm{BiMeO}_{3}-\mathrm{PTiO}_{3}$ system, which is usually observed in the electric field-dependent polarization process, can be the main obstacles for its future piezoelectric applications. However, as we have mentioned before, a relatively high piezoelectric charge coefficient of more than $200 \mathrm{pC} / \mathrm{N}$ with a higher Curie temperature range over $400{ }^{\circ} \mathrm{C}$ can improve its prospects for future multifunctional applications, including actuators and sensors.

In this study, we will prepare a BMT-PT system by optimizing the sintering temperature. The main advantages of a BMT-PT piezoelectric system are summarized in Table 1. As seen in Table 1, this system has high piezoelectric properties, a high Curie temperature, and a moderate price. However, as a representative lead content-reduced material, $\mathrm{BiScO}_{3}-\mathrm{PbTiO}_{3}$ also has a high piezoelectric coefficient and a high Curie temperature, but this material is very expensive and not feasible for application in electronic devices. The optimized composition of the BMT-PT system was selected through the phase diagram, and then the morphotropic phase boundary (MPB) was extracted to achieve the maximum piezoelectric properties [14]. In our assumption, we believe that $0.62 \mathrm{Bi}\left(\mathrm{Mg}_{0.5} \mathrm{Ti}_{0.5}\right) \mathrm{O}_{3}-0.38 \mathrm{PbTiO}_{3}$ ceramics have a mixture of rhombohedra and tetragonal structures. This assumption will be tested and discussed after X-ray diffraction (XRD) analysis. Therefore, the composition of $0.62 \mathrm{Bi}\left(\mathrm{Mg}_{0.5} \mathrm{Ti}_{0.5}\right) \mathrm{O}_{3}-0.38 \mathrm{PbTiO}_{3}$ was selected in this experiment [15]. Crystalline properties, including XRD patterns, and electrical properties, including piezoelectric and dielectric properties, will be investigated and discussed.

Table 1. Comparison of piezoelectric properties of $\mathrm{BiMeO}_{3}-\mathrm{PbTiO}_{3}$ and other lead content-reduced ceramics.

\begin{tabular}{|c|c|c|c|c|c|c|}
\hline & $\begin{array}{c}\text { Sintering } \\
\text { Temperature }\end{array}$ & $\begin{array}{c}\text { Dielectric } \\
\text { Permittivity }\end{array}$ & $\begin{array}{c}\text { Curie } \\
\text { Temperature }\end{array}$ & $\begin{array}{l}\text { Piezoelectric } \\
\text { Charge } \\
\text { Coefficient }\end{array}$ & Cost & Reference \\
\hline $\mathrm{BiFeO}_{3}-\mathrm{PbTiO}_{3}$ & $1100^{\circ} \mathrm{C}$ & $\begin{array}{c}500 \text { for } \\
0.3 \mathrm{BF}-0.7 \mathrm{PT}\end{array}$ & $500{ }^{\circ} \mathrm{C}$ & $165 \mathrm{pC} / \mathrm{N}$ & Moderate & {$[12,16]$} \\
\hline $\mathrm{BiScO}_{3}-\mathrm{PbTiO}_{3}$ & & $\begin{array}{c}1450 \text { for } \\
0.36 \mathrm{BS}-0.64 \mathrm{PT}\end{array}$ & $450^{\circ} \mathrm{C}$ & $460 \mathrm{pC} / \mathrm{N}$ & Very High & {$[12,17]$} \\
\hline $\mathrm{BiInO}_{3}-\mathrm{PbTiO}_{3}$ & & $\begin{array}{c}600 \text { for } \\
0.1 \mathrm{BiInO}_{3}-0.9 \mathrm{TiO}_{3}\end{array}$ & $541^{\circ} \mathrm{C}$ & & Moderate & {$[12,18]$} \\
\hline $\mathrm{BiYbO}_{3}-\mathrm{PbTiO}_{3}$ & $1140{ }^{\circ} \mathrm{C}$ & $\begin{array}{c}650 \text { for } \\
0.1 \mathrm{BY}-0.9 \mathrm{PT}\end{array}$ & $590{ }^{\circ} \mathrm{C}$ & $18 \mathrm{pC} / \mathrm{N}$ & Very High & {$[12,19]$} \\
\hline $\begin{array}{c}\mathrm{BNT}-\mathrm{PT} \\
0.55 \mathrm{Bi}\left(\mathrm{Ni}_{1 / 2} \mathrm{Ti}_{1 / 2}\right) \mathrm{O}_{3}- \\
0.45 \mathrm{PbTiO}_{3} \\
\end{array}$ & $1050^{\circ} \mathrm{C}$ & & $400^{\circ} \mathrm{C}$ & $293 \mathrm{pC} / \mathrm{N}$ & Moderate & {$[12,20]$} \\
\hline $\begin{array}{c}\text { BMT-PT } \\
\text { (our samples) }\end{array}$ & $1075^{\circ} \mathrm{C}$ & $\begin{array}{c}625 \text { for } \\
0.62 \mathrm{BMT}-0.38 \mathrm{PT}\end{array}$ & $447^{\circ} \mathrm{C}$ & $237 \mathrm{pC} / \mathrm{N}$ & Moderate & \\
\hline
\end{tabular}

\section{Materials and Methods}

The $0.62 \mathrm{Bi}\left(\mathrm{Mg}_{0.5} \mathrm{Ti}_{0.5}\right) \mathrm{O}_{3}-0.38 \mathrm{PbTiO}_{3}(0.62 \mathrm{BMT}-0.38 \mathrm{PT})$ ceramics were prepared by a standard ceramic sintering technique using the blended oxides method. The raw materials, $\mathrm{Bi}_{2} \mathrm{O}_{3}$, $4 \mathrm{MgCO}_{3} \cdot \mathrm{Mg}(\mathrm{OH})_{2} \cdot 5 \mathrm{H}_{2} \mathrm{O}, \mathrm{TiO}_{2}$, and $\mathrm{PbO}$, were weighed and combined by ball-milling with a $\mathrm{ZrO}_{2}$ ball in ethyl alcohol for $24 \mathrm{~h}$. The blended powders were calcined at $900{ }^{\circ} \mathrm{C}$ for $2 \mathrm{~h}$ in a furnace. The desiccated powders were blended with polyvinyl alcohol (PVA) and compressed into a disk with a diameter of $10 \mathrm{~mm}$ and thickness of $1 \mathrm{~mm}$. The sample was then sintered at various temperatures ranging from 975 to $1100{ }^{\circ} \mathrm{C}\left(975,1000,1025,1050,1075\right.$, and $\left.1100{ }^{\circ} \mathrm{C}\right)$ for $2 \mathrm{~h}$ in a sealed alumina crucible to avoid loss of $\mathrm{Bi}_{2} \mathrm{O}_{3}$ and $\mathrm{PbO}$ due to sublimation. Silver electrodes were formed on both sides of the ceramic plates by screen printing. The poling process was performed in a silicon oil bath at 
$100{ }^{\circ} \mathrm{C}$ with an applied electric field of $1 \mathrm{kV} / \mathrm{mm}$. The crystalline properties were analyzed by XRD using a $\mathrm{Cu} \mathrm{K} \alpha$ radiation source (Bruker ARS), and the electric properties were analyzed by an HP 4294 impedance analyzer. Field emission scanning electron microscopy (FESEM) was used to examine the microstructure. To characterize its piezoelectric and dielectric properties, the piezoelectric charge coefficient and electric field-dependent polarization processes were performed, in this experiment, by employing the Sawyer-Tower method with $0.1 \mathrm{~Hz}$.

\section{Results and Discussion}

Figure 1 shows the XRD patterns for the 0.62BMT-0.38PT systems, which were sintered at various temperatures. The specimens were sintered from 975 to $1100{ }^{\circ} \mathrm{C}$ in steps of $25^{\circ} \mathrm{C}$. Figure 2 displays the (001) XRD peaks of 0.62BMT-0.38PT piezoelectric ceramics according to the sintering temperature range. As shown in Figures 1 and 2, the XRD patterns show very weak variation in peak intensities and positions. This means that the degree of crystallization and d-space of lattice parameters were slightly changed after the sintering process. As observed in Figure 2, the (001) peak position of $0.62 \mathrm{BMT}-0.38 \mathrm{PT}$ ceramics were shifted to lower angles as the sintering temperature increased. It means that the lattice parameter $\mathrm{c}$ increased as the sintering temperature increased. Furthermore, it seems that 0.62BMT-0.38PT piezoelectric systems have good crystalline structure without a pyrochlore phase.

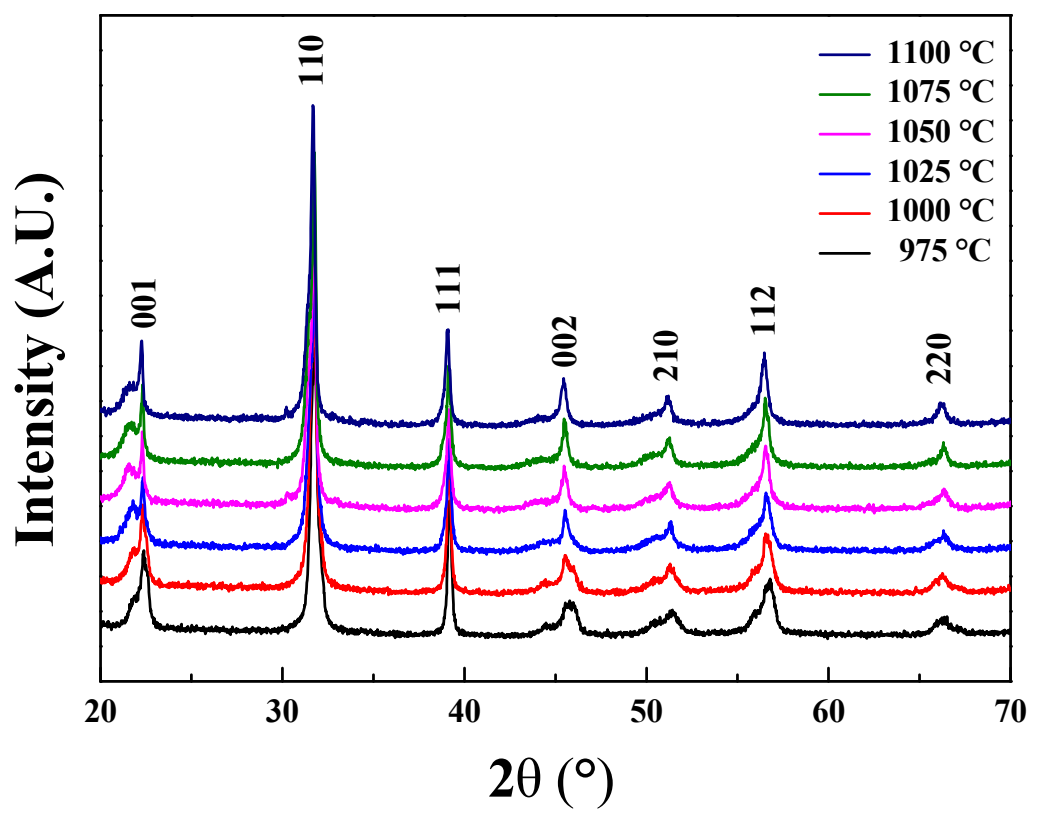

Figure 1. X-ray diffraction (XRD) patterns of $\mathrm{Bi}\left(\mathrm{Mg}_{0.5} \mathrm{Ti}_{0.5}\right) \mathrm{O}_{3}-\mathrm{PbTiO}_{3}$ ceramics according to sintering temperature.

Figure 3 depicts the degree of crystallization for the (001) direction in the 0.62BMT-0.38PT ceramic. The crystallization degree of (001) approached or even exceeded $10 \%$ at the sintering temperature of $1075^{\circ} \mathrm{C}$. This means that the distorted perovskite structure of $0.62 \mathrm{BMT}-0.38 \mathrm{PT}$ ceramics has a high degree of c-axis orientation as sintering temperature increases, which corresponds to the added thermal energy to form the crystalline structure. However, when the sintering temperature was increased beyond $1100{ }^{\circ} \mathrm{C}$, the peak ratio of (001) decreased. We believe this maximum value of peak ratio (001) at $1075^{\circ} \mathrm{C}$ and decreased peak ratio at $1100^{\circ} \mathrm{C}$ are probably related with the crystallization degree. Therefore, we can argue that a sintering temperature of $1075^{\circ} \mathrm{C}$ is the optimized sintering temperature owing to the increased (001) relative intensities. 


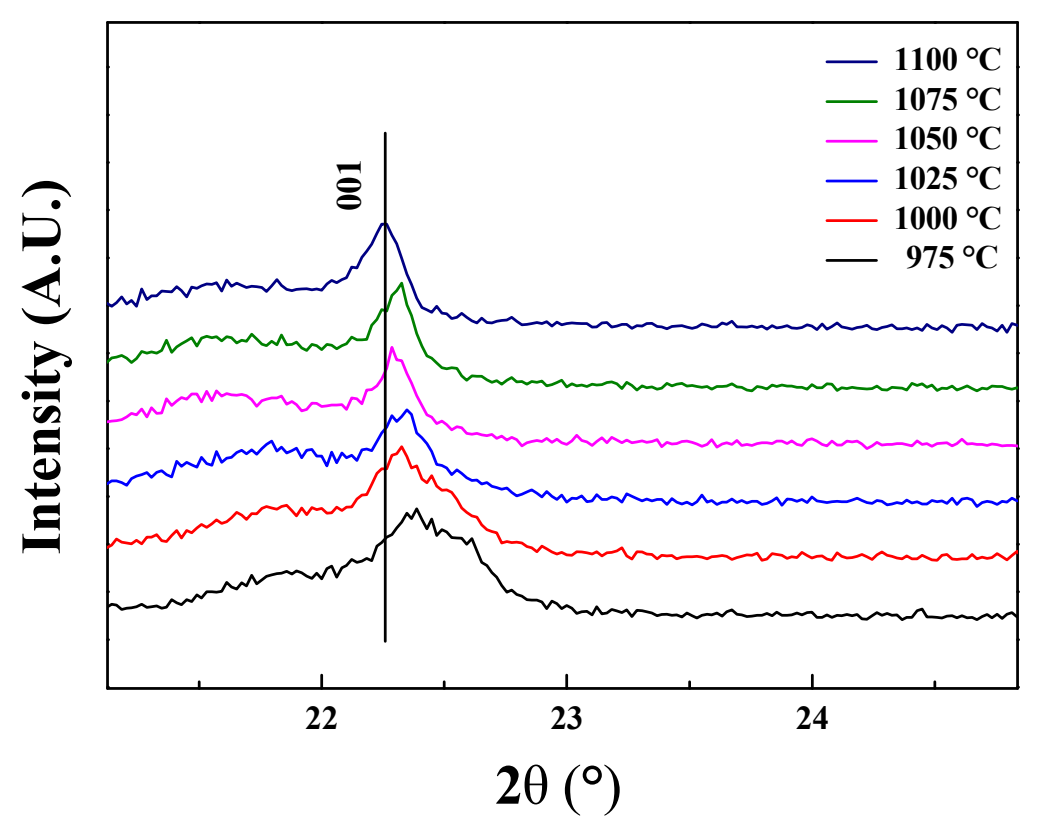

Figure 2. $\mathrm{XRD}(001)$ peak shifts of $\mathrm{Bi}\left(\mathrm{Mg}_{0.5} \mathrm{Ti}_{0.5}\right) \mathrm{O}_{3}-\mathrm{PbTiO}_{3}$ ceramics according to sintering temperature.

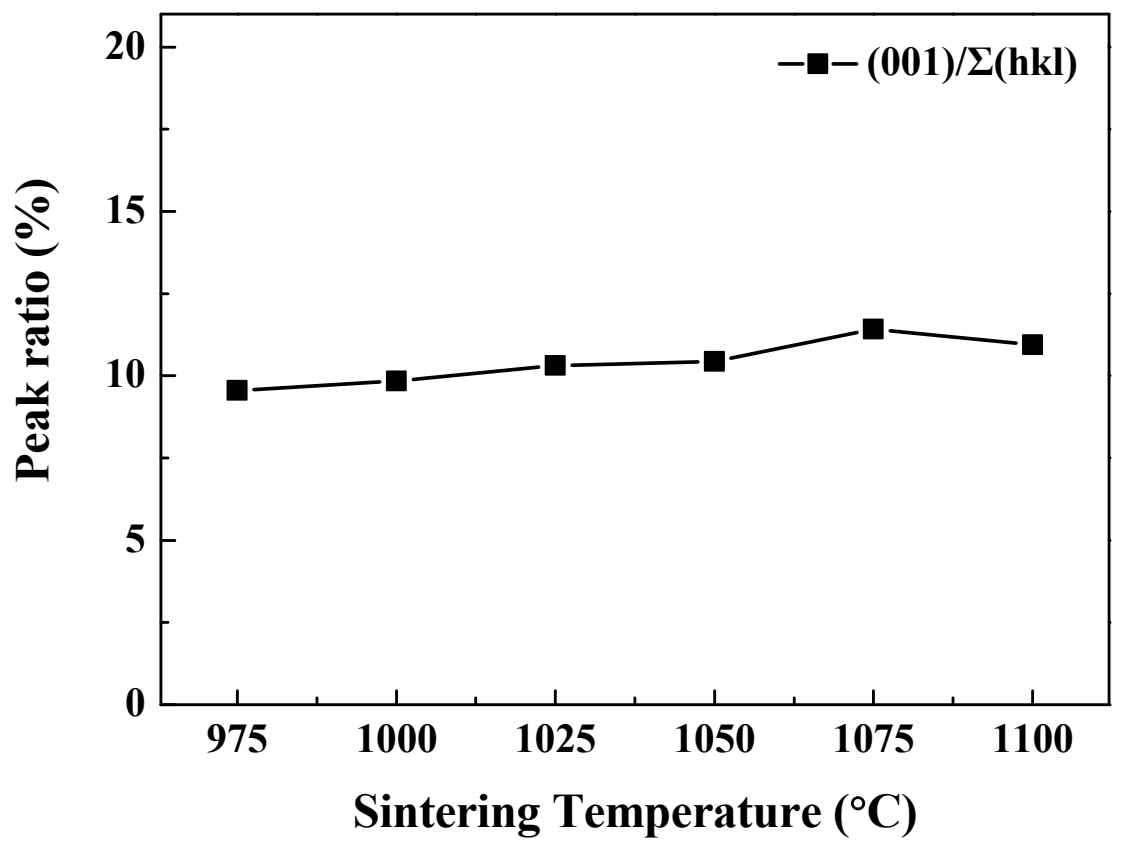

Figure 3. Peak ratio (001) of $\mathrm{Bi}\left(\mathrm{Mg}_{0.5} \mathrm{Ti}_{0.5}\right) \mathrm{O}_{3}-\mathrm{PbTiO}_{3}$ ceramics according to sintering temperature.

Figure 4 shows the FESEM images for the 0.62BMT-0.38PT ceramics, which were sintered at various temperatures. As shown in the FESEM images, the grain size of $0.62 \mathrm{BMT}-0.38 \mathrm{PT}$ ceramics increased as the sintering temperature increased. At a sintering temperature of $1075^{\circ} \mathrm{C}, 0.62 \mathrm{BMT}-0.38 \mathrm{PT}$ ceramics showed a large grain size with a dense structure. Due to this highly dense structure, $0.62 \mathrm{BMT}-0.38 \mathrm{PT}$ ceramics that were sintered at $1075^{\circ} \mathrm{C}$ showed the highest piezoelectric and dielectric properties among the specimens. However, as the sintering temperature of $1100{ }^{\circ} \mathrm{C}$ was attained, the grain shape was distorted, and the size was decreased. 


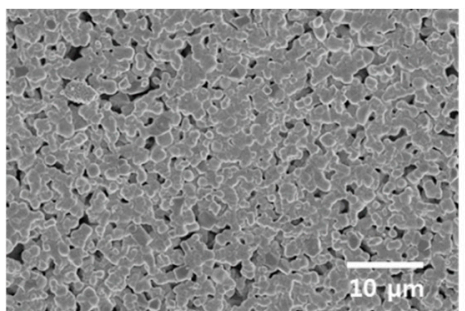

$975^{\circ} \mathrm{C}$

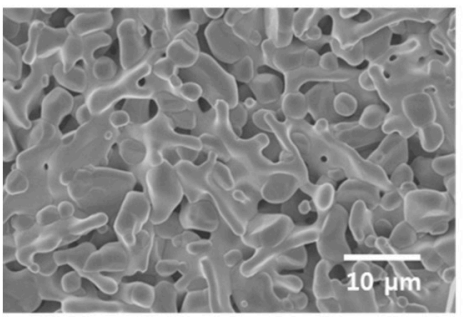

$1050{ }^{\circ} \mathrm{C}$

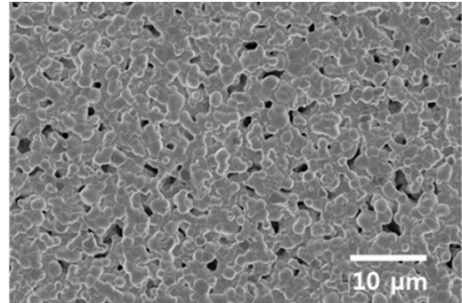

$1000^{\circ} \mathrm{C}$

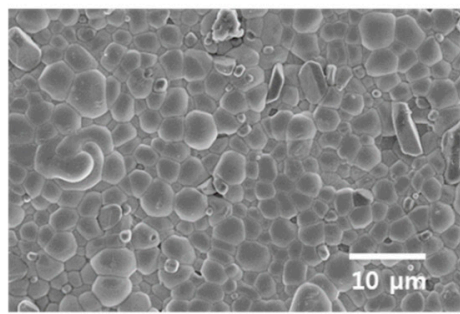

$1075^{\circ} \mathrm{C}$

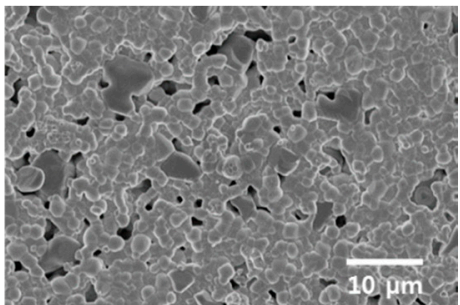

$1025^{\circ} \mathrm{C}$

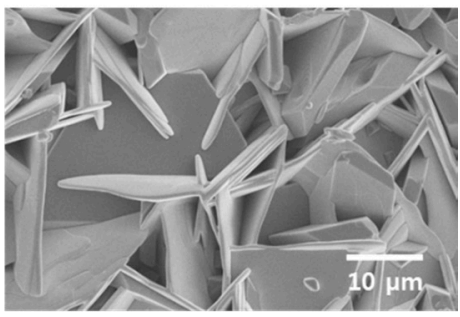

$1100{ }^{\circ} \mathrm{C}$

Figure 4. Field-emission scanning electron microscopy (FESEM) images of $\mathrm{Bi}\left(\mathrm{Mg}_{0.5} \mathrm{Ti}_{0.5}\right) \mathrm{O}_{3}-\mathrm{PbTiO}_{3}$ according to sintering temperature.

Figure 5 reveals the bulk and theoretical density of 0.62BMT-0.38PT ceramics depending on the sintering temperature. As the sintering temperature increased, the density increased up to $1075{ }^{\circ} \mathrm{C}$ and then decreased. This behavior is similar to that of grain size as observed in the FESEM images. As the sintering temperature increased, 0.62BMT-0.38PT ceramics became crystallized, therefore, the density was increased. However, as the sintering temperature was further increased up to $1100{ }^{\circ} \mathrm{C}$, the density decreased. We believe that this decreased bulk density comes from the oversintered phase of 0.62BMT-0.38PT ceramics. It also seems that the bulk density of 0.62BMT-0.38PT ceramics correlated with the FESEM images, which is described in Figure 4.

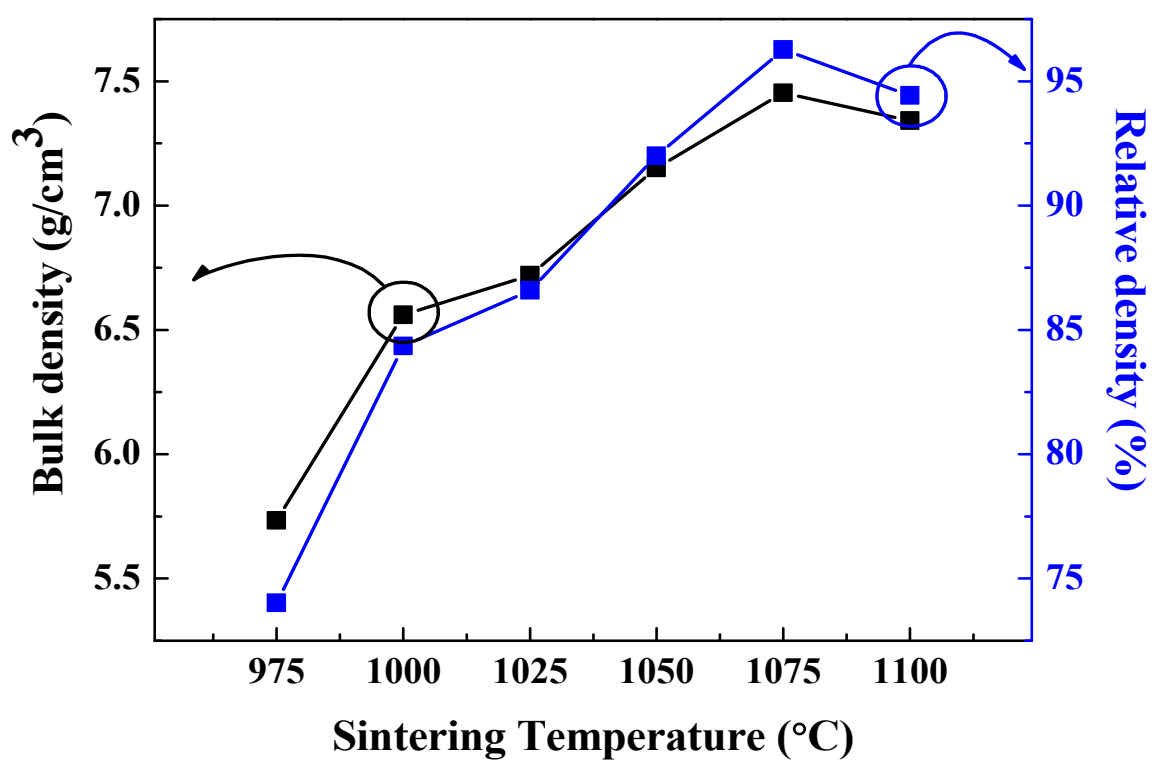

Figure 5. Bulk density and relative density of $\mathrm{Bi}\left(\mathrm{Mg}_{0.5} \mathrm{Ti}_{0.5}\right) \mathrm{O}_{3}-\mathrm{PbTiO}_{3}$ ceramics according to sintering temperature.

Figure 6 shows the frequency-dependent dielectric permittivity of 0.62BMT-0.38PT ceramics from $1 \mathrm{kHz}$ to $1 \mathrm{MHz}$. Clearly, 0.62BMT-0.38PT ceramics sintered at the $1075^{\circ} \mathrm{C}$ showed the highest 
dielectric permittivity of 625 at $1 \mathrm{kHz}$, whereas those sintered at $975^{\circ} \mathrm{C}$ showed the lowest dielectric permittivity of 480 at $1 \mathrm{kHz}$.

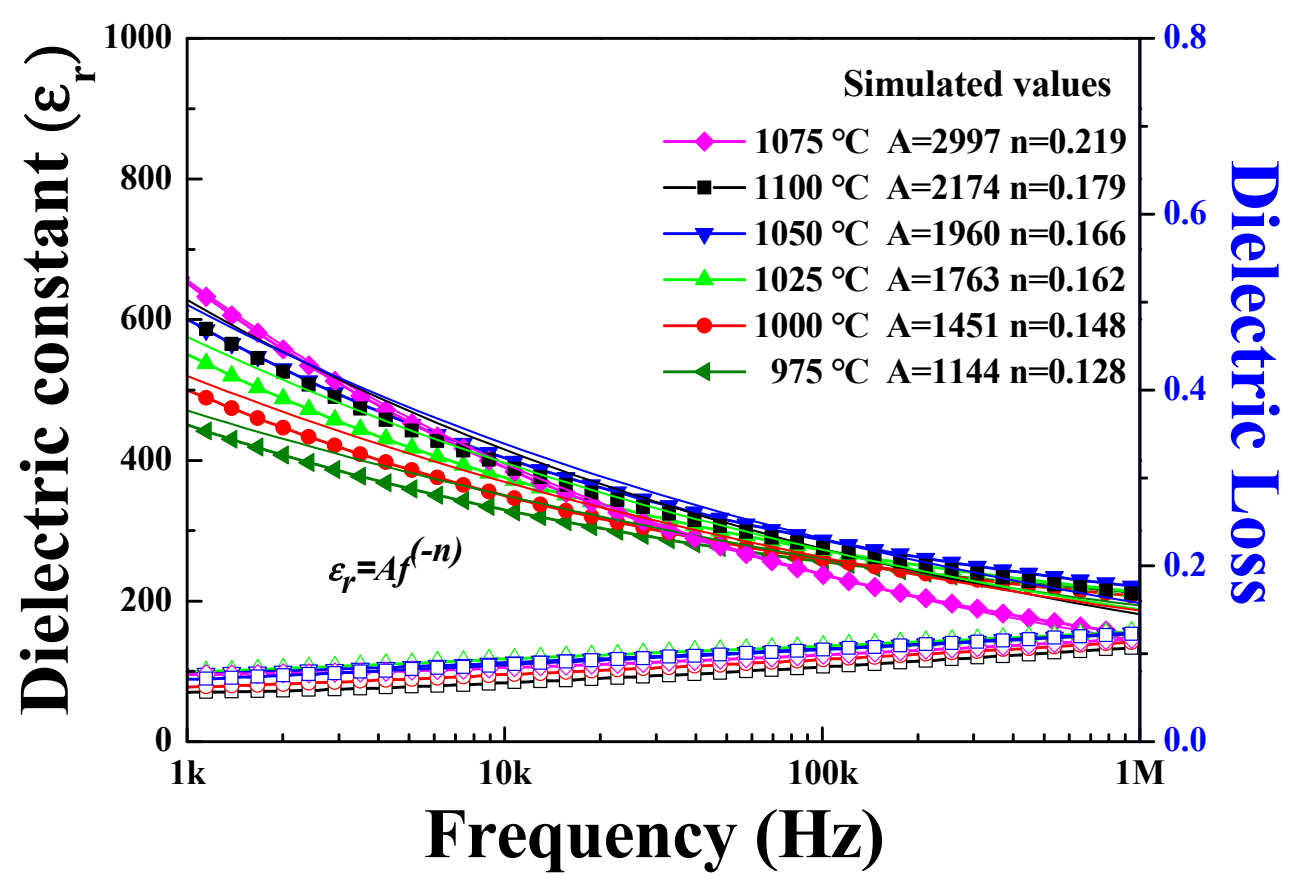

Figure 6. Frequency-dependent dielectric permittivity of $\mathrm{Bi}\left(\mathrm{Mg}_{0.5} \mathrm{Ti}_{0.5}\right) \mathrm{O}_{3}-\mathrm{PbTiO}_{3}$ ceramics according to sintering temperature.

It seems that $0.62 \mathrm{BMT}-0.38 \mathrm{PT}$ ceramics have high dielectric permittivity ranges at room temperature. The solid lines indicate the simulation fitting from the measured samples with the power law. The power law of $\varepsilon_{\mathrm{r}}=A f^{-\mathrm{n}}$ was employed to fit dielectric relaxation behavior [21]. Ceramics of 0.62BMT-0.38PT sintered at $1075{ }^{\circ} \mathrm{C}$ showed the highest exponent of 0.219 among the specimens. Compared to other specimens, this means that the variance of dielectric permittivity for 0.62BMT-0.38PT ceramics sintered at $1075^{\circ} \mathrm{C}$ has the highest exponent of 0.219 and highest dielectric permittivity of 625 . The high exponent value of 0.219 from the power law equation means that many different dipoles were involved in the relaxation process with continuous freezing out of dipoles with increasing frequency range. Therefore, $0.62 \mathrm{BMT}-0.38 \mathrm{PT}$ piezoelectric ceramics showed rapid change in the dielectric constant when increasing the frequency range. Owing to this high relaxation behavior, $0.62 \mathrm{BMT}-0.38 \mathrm{PT}$ ceramics sintered at $1075^{\circ} \mathrm{C}$ have the highest piezoelectric properties. The dielectric permittivity of $0.62 \mathrm{BMT}-0.38 \mathrm{PT}$ ceramics sintered at $1075^{\circ} \mathrm{C}$ also have the highest dielectric permittivity values.

Figure 7 shows the electric field-dependent polarizations for 0.62BMT-0.38PT ceramics with different sintering temperatures. As the sintering temperature was increased, the polarization increased. In particular, 0.62BMT-0.38PT ceramics sintered at 1075 and $1100{ }^{\circ} \mathrm{C}$ showed higher ferroelectric properties compared to other specimens. It seems that the higher the sintering temperature, the larger the polarization behavior. In the case of the electric field-dependent polarization case, sintering temperature dependencies are more clearly observed.

Figure 8 shows the piezoelectric charge coefficient and electromechanical coupling coefficient of 0.62BMT-0.38PT ceramics depending on the sintering temperature range. The piezoelectric charge coefficient and electromechanical coupling coefficient of $0.62 \mathrm{BMT}-0.38 \mathrm{PT}$ ceramics sintered at $1075{ }^{\circ} \mathrm{C}$ showed the highest values of $240 \mathrm{pC} / \mathrm{N}$ and $47 \%$, respectively. These high piezoelectric charge coefficient and electromechanical coupling coefficient coincided well with the dense behavior observed in FESEM images and bulk densities. 


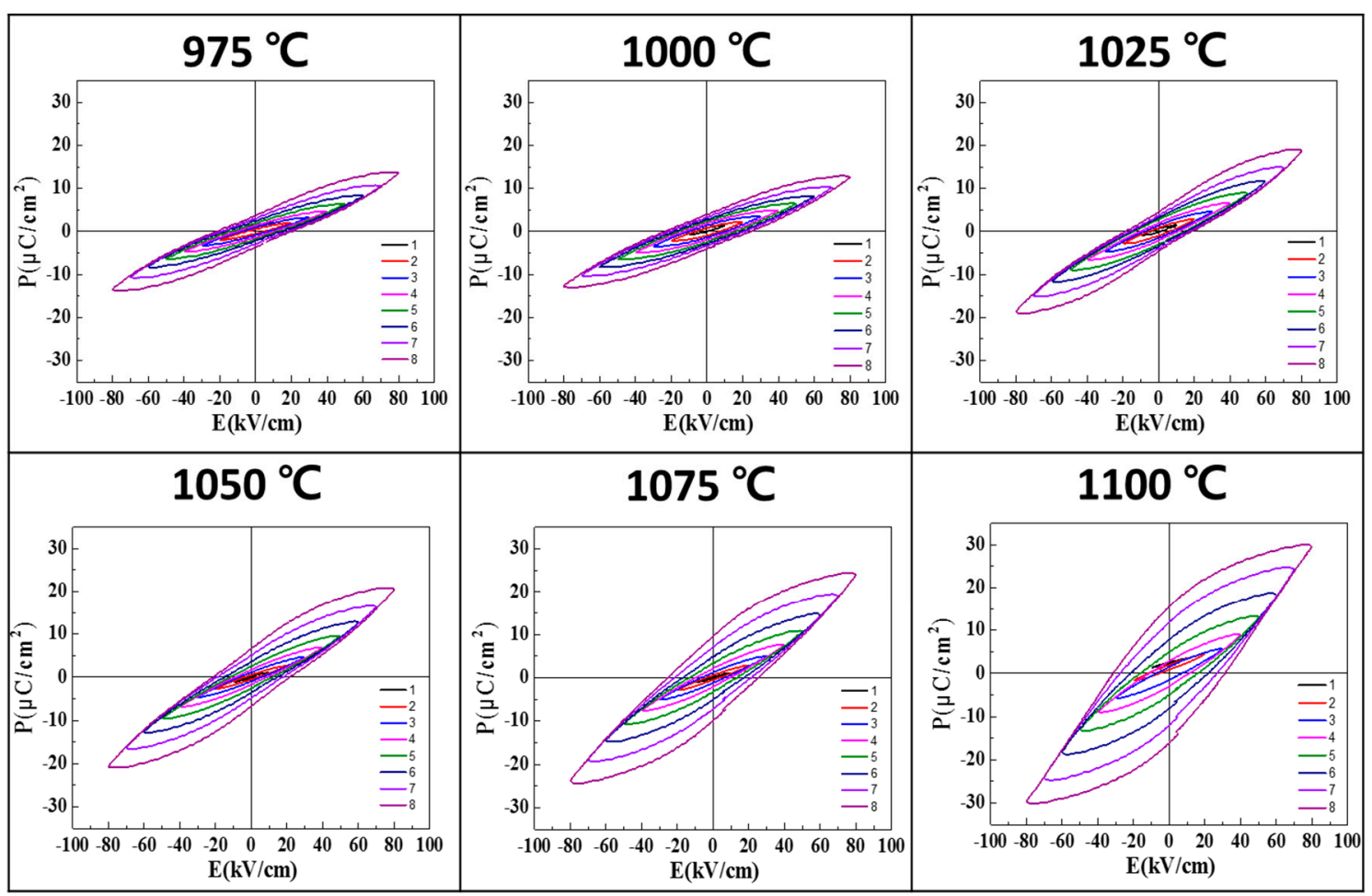

Figure 7. Electric field-dependent polarization properties of $\mathrm{Bi}\left(\mathrm{Mg}_{0.5} \mathrm{Ti}_{0.5}\right) \mathrm{O}_{3}-\mathrm{PbTiO}_{3}$ according to sintering temperature.

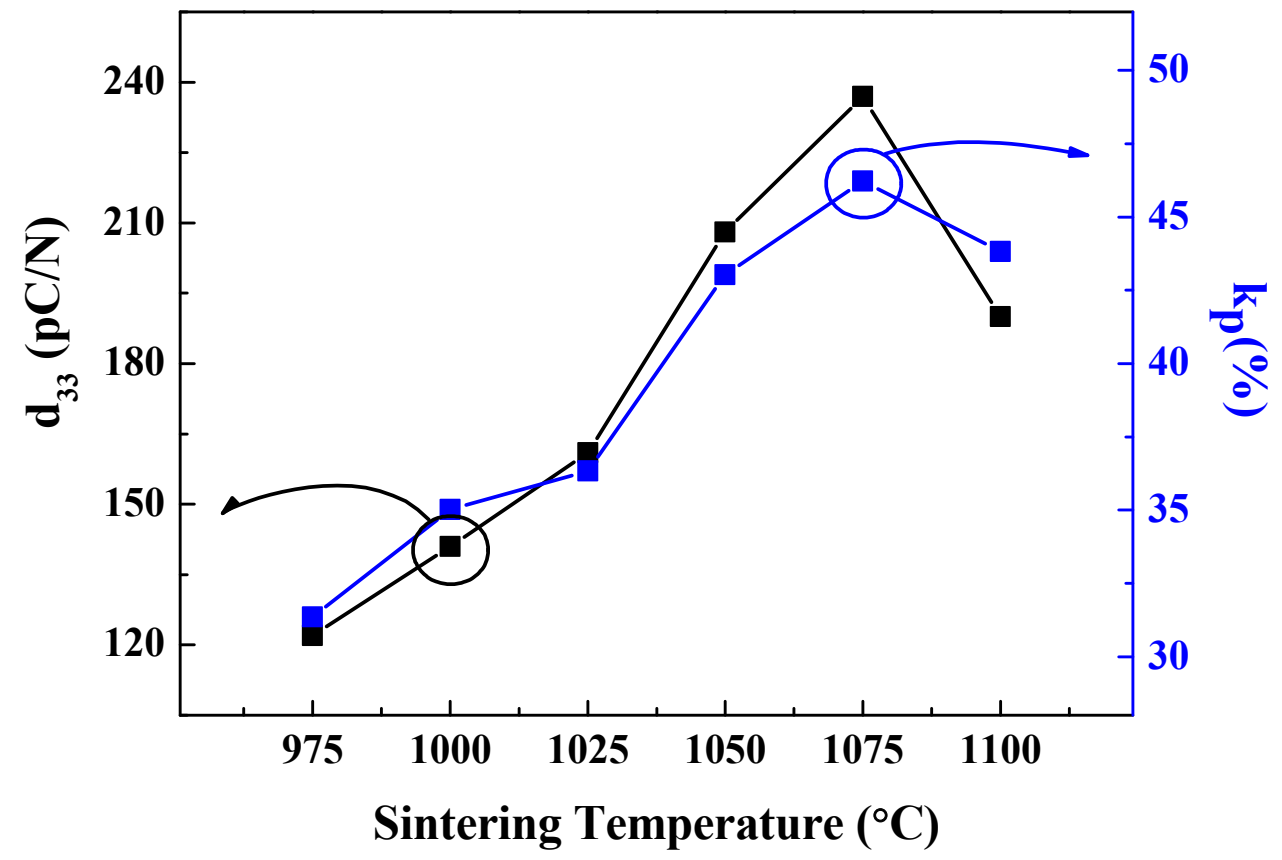

Figure 8. Piezoelectric coefficient $\mathrm{d}_{33}$ and $\mathrm{k}_{\mathrm{p}}$ of $\mathrm{Bi}\left(\mathrm{Mg}_{0.5} \mathrm{Ti}_{0.5}\right) \mathrm{O}_{3}-\mathrm{PbTiO}_{3}$ according to sintering temperature.

Figure 9 displays the piezoelectric voltage coefficient and figure of merit (FoM) of 0.62BMT-0.38PT ceramics. As shown in Figure 9, the highest value of the piezoelectric voltage coefficient of $41 \times 10^{-3} \mathrm{Vm} / \mathrm{N}$ and FoM of $9.8 \mathrm{pm}^{2} / \mathrm{N}$ were obtained for the 0.62BMT-0.38PT ceramics. Since the piezoelectric voltage coefficient was derived from the piezoelectric charge coefficient and dielectric constant, $g_{33}=d_{33} / \varepsilon_{\mathrm{r}}$, we can expect that the piezoelectric voltage coefficient of 0.62BMT-0.38PT ceramics sintered at $1075^{\circ} \mathrm{C}$ has the highest values of $41 \times 10^{-3} \mathrm{Vm} / \mathrm{N}$ and FoM of $9.8 \mathrm{pm}^{2} / \mathrm{N}$. 


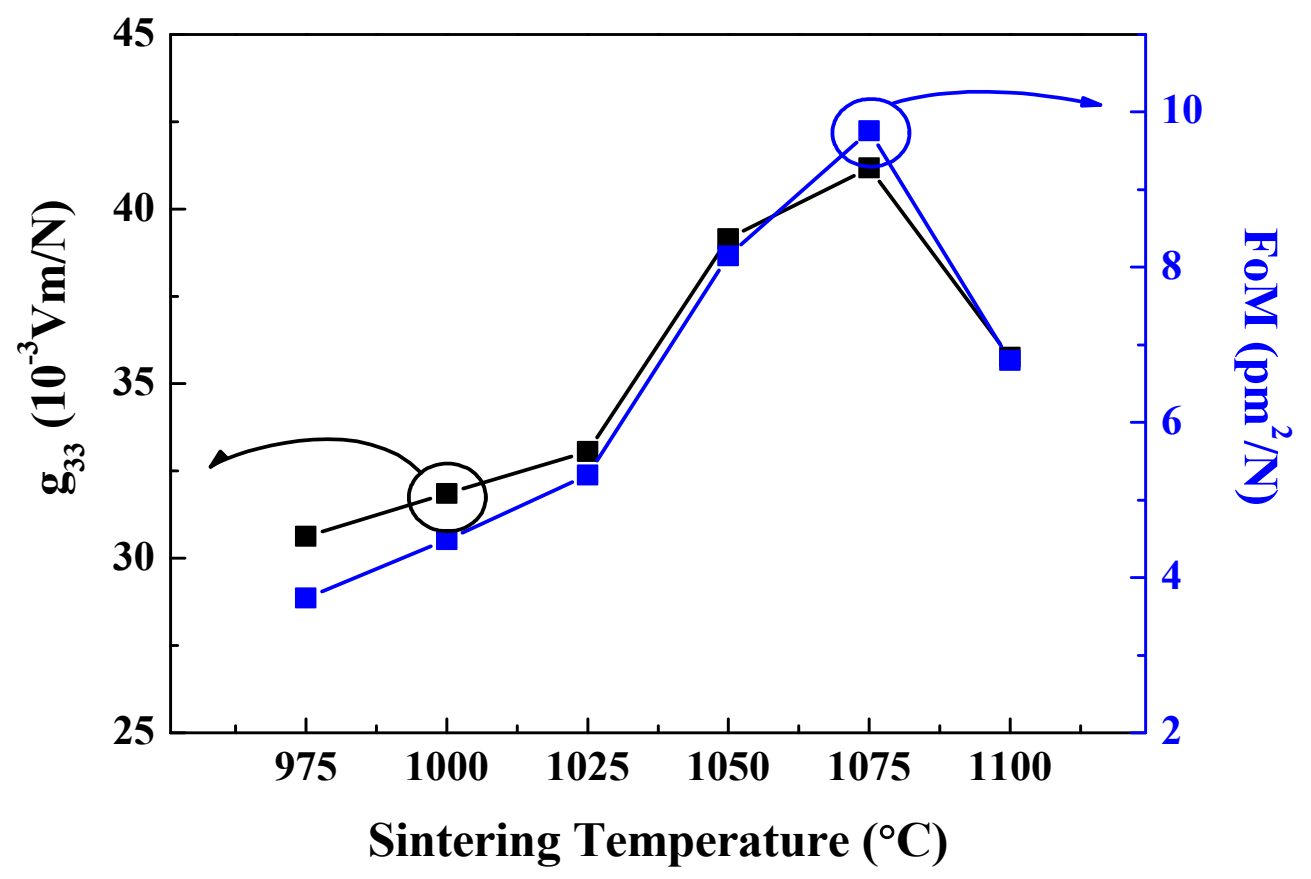

Figure 9. Piezoelectric voltage coefficient and figure of merit (FoM) of $\mathrm{Bi}\left(\mathrm{Mg}_{0.5} \mathrm{Ti}_{0.5}\right) \mathrm{O}_{3}-\mathrm{PbTiO}_{3}$ according to sintering temperature.

Figure 10 shows the temperature-dependent dielectric permittivity $\varepsilon_{\mathrm{r}}$ of the $0.62 \mathrm{BMT}-0.38 \mathrm{PT}$ ceramic sintered from 975 to $1100{ }^{\circ} \mathrm{C}$. At sintering temperatures of $975,1000,1025,1050,1075$, and $1100{ }^{\circ} \mathrm{C}$, the Curie temperature was $346.9,374.5,386.5,389.2,447.2$, and $428.5^{\circ} \mathrm{C}$, respectively. As the sintering temperature increased from 975 to $1075{ }^{\circ} \mathrm{C}$, the Curie temperature increased from 346.9 to $447.2{ }^{\circ} \mathrm{C}$. As the sintering temperature reached $1100^{\circ} \mathrm{C}$, the Curie temperature suddenly decreased. Compared to other specimens, BMT-PT ceramics sintered at $975^{\circ} \mathrm{C}$ had the lowest Curie temperature of $346.9{ }^{\circ} \mathrm{C}$, whereas those sintered at $1075^{\circ} \mathrm{C}$ had the highest Curie temperature of $447.2^{\circ} \mathrm{C}$.

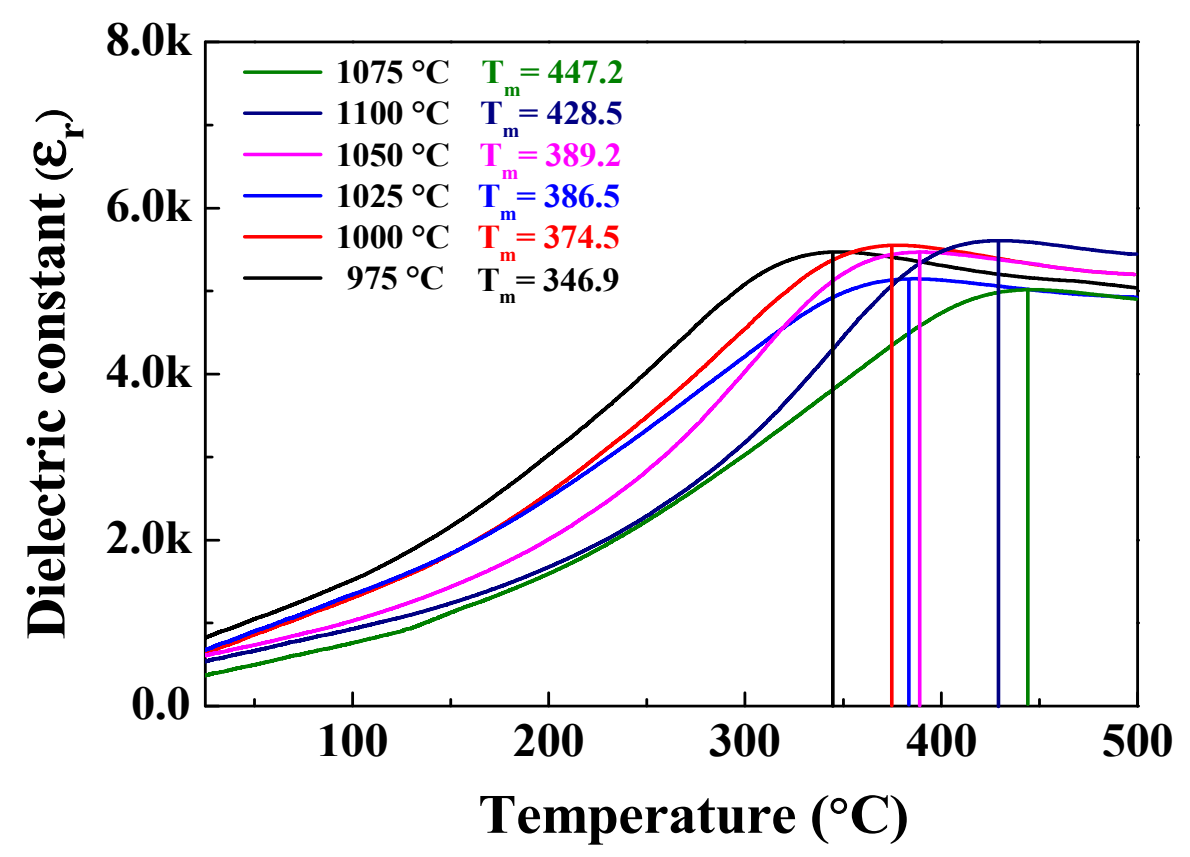

Figure 10. Temperature-dependent relative dielectric constant $\varepsilon_{\mathrm{r}}$ of $\mathrm{Bi}\left(\mathrm{Mg}_{0.5} \mathrm{Ti}_{0.5}\right) \mathrm{O}_{3}-\mathrm{PbTiO}_{3}$ ceramic according to sintering temperature. 


\section{Conclusions}

In this research, the piezoelectric and dielectric properties of 0.62BMT-0.38PT ceramics with different sintering temperatures were investigated and discussed. A very high Curie temperature of $447^{\circ} \mathrm{C}$ was recorded for $0.62 \mathrm{BMT}-0.38 \mathrm{PT}$ ceramics sintered at $1075^{\circ} \mathrm{C} .0 .62 \mathrm{BMT}-0.38 \mathrm{PT}$ piezoelectric ceramics have a reduced lead content and high piezoelectric charge coefficient of $237 \mathrm{pC} / \mathrm{N}$ and can, therefore, be used in piezoelectric applications where the environment is harsh. Even though 0.62BMT-0.38PT ceramics had a lower lead content compared to $\mathrm{Pb}\left(\mathrm{Zr}_{0.5} \mathrm{Ti}_{0.5}\right) \mathrm{O}_{3}$-based conventional piezoelectric ceramics, $0.62 \mathrm{BMT}-0.38 \mathrm{PT}$ piezoelectric ceramics still have excellent piezoelectric and dielectric properties with a high Curie temperature. We believe that the high piezoelectric properties of $0.62 \mathrm{BMT}-0.38 \mathrm{PT}$ are related to relaxation behavior. We believe $0.62 \mathrm{BMT}-0.38 \mathrm{PT}$ ceramics, with their lower lead content, can act as alternative materials for lead-based piezoelectric materials. Reducing the lead content of piezoelectric materials is expected to help not only by preventing environmental pollution on Earth but, also, by being more useful as a piezoelectric material because of its excellent characteristics compared to lead-free piezoelectric material. For example, 0.62BMT-0.38PT ceramics can be applied in piezoelectric transducers or as a sintering aid, using ferroelectricity, that does not change at a high temperature.

Author Contributions: M.Y.P. performed the experiments and wrote the paper; J.-H.J. made some additional experiment and analysis and J.-H.K. analyzed experimental data and wrote the paper.

Funding: This research was supported by the MSIP, Korea, under the ITRC support program (IITP-2018-2014-1-00636) supervised by the IITP and supported by the Human Resources Development (No. 20184030202070) of the Korea Institute of Energy Technology Evaluation and Planning (KETEP) grant funded by the Korea government Ministry of Trade, Industry and Energy.

Conflicts of Interest: The authors declare no conflict of interest.

\section{References}

1. Wang, L.; Song, T.K.; Lee, S.C.; Cho, J.H.; Sakka, Y. Effect of $\mathrm{Bi}(\mathrm{B}) \mathrm{O}_{3}$ perovskite substitution on enhanced tetragonality and ferroelectric transition temperature in $\mathrm{Pb}(\mathrm{Zr}, \mathrm{Ti}) \mathrm{O}_{3}$ ceramics. Mater. Chem. Phys. 2011, 129, 322-325. [CrossRef]

2. Matko, V.; Milanovic, M. Temperature-compensated capacitance-frequency converter with high resolution. Sens. Actuators A 2014, 220, 262-269. [CrossRef]

3. Matko, V. Next Generation AT-Cut Quartz Crystal Sensing Devices. Sensors 2011, 11, 4474-4482. [CrossRef] [PubMed]

4. Nie, J.; Liu, J.; Li, N.; Meng, X. Dew point measurement using dual quartz crystal resonator sensor. Sens. Actuators B 2017, 246, 792-799. [CrossRef]

5. Li, J.-F.; Wang, K. Ferroelectric and Piezoelectric Properties of Fine-Grained $\mathrm{Na}_{0.5} \mathrm{~K}_{0.5} \mathrm{NbO}_{3}$ Lead-Free Piezoelectric Ceramics Prepared by Spark Plasma Sintering. J. Am. Ceram. Soc. 2006, 89, 706-709. [CrossRef]

6. Takenaka, T.; Nagata, H. Current status and prospects of lead-free piezoelectric ceramics. J. Eur. Ceram. Soc. 2005, 25, 2693-2700. [CrossRef]

7. Baettig, P.; Schelle, C.F.; LeSar, R.; Waghmare, U.V.; Spaldin, N.A. Theoretical Prediction of New High-Performance Lead-Free Piezoelectric. Chem. Mater. 2005, 17, 1376-1380. [CrossRef]

8. Saleem, M.; Hwan, L.D.; Kim, I.-S.; Kim, M.-S.; Maqbool, A.; Nisar, U.; Pervez, S.A.; Farooq, U.; Farooq, M.U.; Khalil, H.M.W.; et al. Revealing of Core Shell Effect on Frequency-Dependent Properties of Bi-based Relaxor/Ferroelectric Ceramic Composites. Sci. Rep. 2018, 8, 14146. [CrossRef] [PubMed]

9. Yabuta, H.; Shimada, M.; Watanabe, T.; Hayashi, J.; Kubota, M.; Miura, K.; Fukui, T.; Fujii, I.; Wada, S. Microstructure of $\mathrm{BaTiO}_{3}-\mathrm{Bi}\left(\mathrm{Mg}_{1 / 2} \mathrm{Ti}_{1 / 2}\right) \mathrm{O}_{3}-\mathrm{BiFeO}_{3}$ Piezoelectric Ceramics. Jpn. J. Appl. Phys. 2012, 51, 09LD04. [CrossRef]

10. Leontsev, S.O.; Eitel, R.E. Dielectric and Piezoelectric Properties in Mn-Modified (1-x) $\mathrm{BiFeO}_{3}-\mathrm{xBaTiO}_{3}$ Ceramics. J. Am. Ceram. Soc. 2009, 92, 2957-2961. [CrossRef]

11. Jiang, M.; Liu, X.; Chen, G.; Zhou, C. Dielectric and piezoelectric properties of $\mathrm{LiSbO}_{3}$ doped 0.995 $\mathrm{K}_{0.5} \mathrm{Na}_{0.5} \mathrm{NbO}_{3}-0.005 \mathrm{BiFeO}_{3}$ piezoelectric ceramics. Mater. Lett. 2009, 63, 1262-1265. [CrossRef] 
12. Rai, R.; Kholkin, A.L.; Sharma, S. Multiferroic properties of $\mathrm{BiFeO}_{3}$ doped $\mathrm{Bi}(\mathrm{MgTi}) \mathrm{O}_{3}-\mathrm{PbTiO}_{3}$ ceramic system. J. Alloys Comps. 2010, 506, 815-819. [CrossRef]

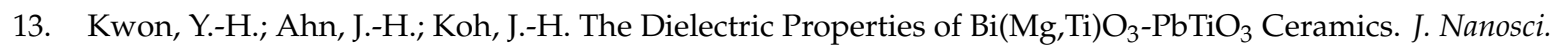
Nanotechnol. 2016, 16, 12927-12929. [CrossRef]

14. Randall, C.A.; Eitel, R.; Jones, B.; Shrout, T.R. Investigation of a high Tc piezoelectric system: (1-x) Bi $\left(\mathrm{Mg}_{1 / 2} \mathrm{Ti}_{1 / 2}\right) \mathrm{O}_{3}-(\mathrm{x}) \mathrm{PbTiO}_{3}$. J. Appl. Phys. 2014, 95, 3633-3639. [CrossRef]

15. Zhang, Q.; Li, Z.; Li, F.; Xu, Z.; Yao, X. Temperature Dependence of Dielectric/Piezoelectric Properties of (1-x) $\mathrm{Bi}\left(\mathrm{Mg}_{1 / 2} \mathrm{Ti}_{1 / 2}\right) \mathrm{O}_{3}-\mathrm{PbTiO}_{3}$ Ceramics with an MPB Composition. J. Am. Ceram. Soc. 2010, 93, 3330-3334. [CrossRef]

16. Zhao, H.; Hou, Y.; Yu, X.; Zheng, M.; Zhu, M. Construction of high $\mathrm{Tc} \mathrm{BiScO}_{3}-\mathrm{BiFeO}_{3}-\mathrm{PbTiO}_{3}$ and its enhanced piezoelectric properties by sintering in oxygen atmosphere. J. Appl. Phys. 2018, 124, 194103. [CrossRef]

17. Zhang, S.; Alberta, E.F.; Eitel, R.E.; Randall, C.A.; Shrout, T.R. Elastic, Piezoelectric, and Dielectric

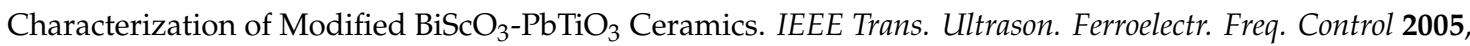
52, 2131-2139. [CrossRef] [PubMed]

18. Qin, B.-Q.; Chen, Y.; Jiang, Y.; Jiang, Y.; Yue, X.; Xiao, D.; Zhu, J. Preparation and Characterization of $(1-\mathrm{x}) \mathrm{BiInO}_{3}-\mathrm{xbTiO}_{3}$ ceramics. In Proceedings of the 2007 Sixteenth IEEE International Symposium on the Applications of Ferroelectrics, Nara, Japan, 27-31 May 2007; pp. 616-617.

19. Gao, F.; Hong, R.; Liu, J.; Li, Z.; Cheng, L.; Tian, C. Phase formation and characterization of high Curie temperature $\mathrm{xBiYbO}_{3}-(1-\mathrm{x}) \mathrm{PbTiO}_{3}$ piezoelectric ceramics. J. Eur. Ceram. Soc. 2009, 29, 1687-1693.

20. Jiang, S.; Zhu, Z.; Zhang, L.; Xiong, X.; Yi, J.; Zeng, Y.; Liu, W.; Wang, Q.; Han, K.; Zhang, G. Electrical properties of $\mathrm{Bi}\left(\mathrm{Ni}_{1 / 2} \mathrm{Ti}_{1 / 2}\right) \mathrm{O}_{3}-\mathrm{PbTiO}_{3}$ high- $\mathrm{T}_{\mathrm{C}}$ piezoelectric ceramics fabricated by the microwave sintering process. Mater. Sci. Eng. B Solid State Mater. Adv. Technol. 2014, 179, 36-40. [CrossRef]

21. Weron, K.; Stanislavsky, A.; Jurlewicz, A.; Meerschaert, M.M.; Scheffler, H.-P. Clustered continuous-time random walks: diffusion and relaxation consequences. Proc. R. Soc. A 2012, 468, 1615-1628. [CrossRef] [PubMed]

(C) 2019 by the authors. Licensee MDPI, Basel, Switzerland. This article is an open access article distributed under the terms and conditions of the Creative Commons Attribution (CC BY) license (http://creativecommons.org/licenses/by/4.0/). 